\title{
Automatic Classification of Arterial and Venous Flow in Super-resolution Ultrasound Images of Rat Kidneys
}

Taghavi, Iman; Andersen, Sofie Bech; Søgaard, Stinne Byrholdt; Nielsen, Michael Bachmann; Sørensen, Charlotte Mehlin; Stuart, Matthias Bo; Jensen, Jørgen Arendt

\section{Published in:}

Proceedings of 2021 IEEE International Ultrasonics Symposium

Link to article, DOI:

10.1109/IUS52206.2021.9593655

Publication date:

2021

Document Version

Peer reviewed version

Link back to DTU Orbit

Citation (APA):

Taghavi, I., Andersen, S. B., Søgaard, S. B., Nielsen, M. B., Sørensen, C. M., Stuart, M. B., \& Jensen, J. A. (2021). Automatic Classification of Arterial and Venous Flow in Super-resolution Ultrasound Images of Rat Kidneys. In Proceedings of 2021 IEEE International Ultrasonics Symposium IEEE.

https://doi.org/10.1109/IUS52206.2021.9593655

\section{General rights}

Copyright and moral rights for the publications made accessible in the public portal are retained by the authors and/or other copyright owners and it is a condition of accessing publications that users recognise and abide by the legal requirements associated with these rights.

- Users may download and print one copy of any publication from the public portal for the purpose of private study or research.

- You may not further distribute the material or use it for any profit-making activity or commercial gain

- You may freely distribute the URL identifying the publication in the public portal 


\title{
Automatic Classification of Arterial and Venous Flow in Super-resolution Ultrasound Images of Rat Kidneys
}

\author{
Iman Taghavi ${ }^{1}$, Sofie Bech Andersen ${ }^{2,3}$, Stinne Byrholdt Søgaard ${ }^{3}$, Michael Bachmann Nielsen ${ }^{2}$, \\ Charlotte Mehlin Sørensen ${ }^{3}$, Matthias Bo Stuart ${ }^{1}$, and Jørgen Arendt Jensen ${ }^{1}$ \\ ${ }^{1}$ Center for Fast Ultrasound Imaging, DTU Health Tech., Technical University of Denmark \\ ${ }^{2}$ Department of Diagnostic Radiology, Rigshospitalet, Denmark \\ ${ }^{3}$ Department of Biomedical Sciences, University of Copenhagen, Denmark
}

\begin{abstract}
Velocity is one of the clinically interesting parameters. A number of studies have shown the ability of superresolution (SR) ultrasound imaging to visualize this parameter using velocity maps. However, manual separation of the velocity estimates for arteries from veins can be quite demanding. This study used the anatomical knowledge of rat kidneys for automatic classification of arterial and venous blood velocities in SR images and measured their variations in the medullary regions of four healthy Sprague-Dawley rat kidneys. The measurements were conducted using a modified bk5000 scanner (BK Medical, Herlev, Denmark) and a BK 9009 linear array probe with a pulse amplitude modulation scheme. Ten minutes of acquired B-mode and contrast images with frame-rate of $54 \mathrm{~Hz}$ were processed using a SR processing pipeline. The micro-bubble trajectories were filtered using coarse anatomy labels for classification of arterial and venous flow. The velocity estimates of separated arterioles and venules of the outer medulla showed separation of data in all rats. A Wilcoxon test showed that this difference was statistically significant $(p=0.002)$. Considering the sample size for this study, the $t$-distributions predicted that the median velocity in the $\mathrm{OM}$ arterioles and venules were in the range of $0.84 \pm$ $0.09 \mathrm{~mm} / \mathrm{s}$ and $0.70 \pm 0.07 \mathrm{~mm} / \mathrm{s}$ with $95 \%$ confidence. The result showed how the blood flow in outer medulla arterioles and venules of rat kidneys can be automatically distinguished using the known anatomical information about the renal vasculature.
\end{abstract}

\section{INTRODUCTION}

Ultrasound is well known for its ability for non-invasive flow imaging. Several ultrasound imaging techniques have been used for this purpose. These methods range from color Doppler [1], power Doppler [2], vector flow imaging [3], [4] to contrast-enhanced ultrasound (CEUS) [5], and superresolution ultrasound imaging (SRI) [6]-[9]. The latter technique enables the visualization of flow in the microvasculature. One of the biggest challenges in super-resolution (SR) ultrasound imaging is valid quantification of the huge amount of data within the in vivo SR images. In conventional ultrasound imaging, vessels or regions-of-interest are usually selected manually by an operator for morphological or dynamic quantification. However, the abundance of vessels in SRI makes the manual labeling or identification of arteries and veins quite demanding. In this study, we hypothesized that the prior knowledge about the anatomy of the kidney can be used for automatic classification of arteries and veins. The hypothesis was evaluated by statistics of velocity estimations for separating arteries and veins in the medullary regions of four healthy rat kidneys.

\section{Methods}

Four rat kidneys were scanned during laparotomy using a modified BK5000 scanner and X18L5s transducer (centerfrequency $=6 \mathrm{MHz}$, mechanical index: 0.2, frame-rate: 54 fps). The in vivo kidney data were collected previously for a pilot clinical study [10] and contained 10-minute of Bmode and contrast images for each kidney. The motion-field was estimated locally using the B-mode images [11], [12], for patches of $3 \times 3 \mathrm{~mm}$ with an $80 \%$ overlap. The estimated motion-field was applied to the MB positions detected in the contrast images to compensate for the tissue motion of the rat. The corrected MB positions were then tracked using a series of Kalman filters with different initial conditions to estimate tracks and velocity information [13]. The outer medulla region of the rat kidneys, as well as the arterial flow directions in these regions, were manually labeled. Fig. 1 shows an example of this labeling on the SR velocity map of a kidney, in which the red region is the outer medulla of the kidney, and the yellow arrows indicate the arterial flow directions in this region. A filtration of the track locations and flow directions automatically classified tracks to form separated arterial and venous velocity maps with opposite flow directions. The track filter excluded MBs that were out of the labeled regions or had more than a 45-degree deviation from the artery or vein flow direction. The median of the velocity estimates for the separated arterioles and venules of the outer medulla for 4 rats were compared using a Wilcoxon signed rank test. Assuming that the estimated parameter for 4 regions has a $t$-distribution, the confidence intervals of the median velocity in the separated arterioles and venules were also calculated and compared with each other. 


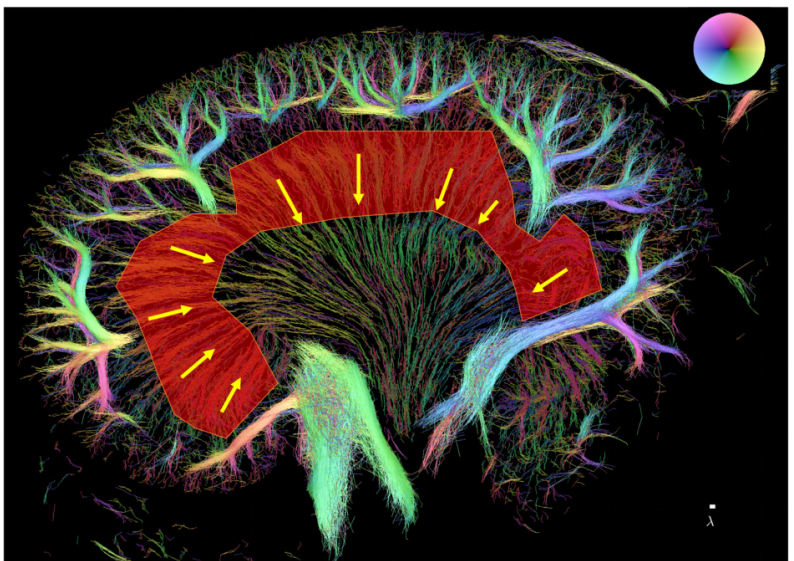

Fig. 1: Anatomical labeling of the kidney: Red region is the outer medulla, and the yellow arrows indicate the arterial flow direction. The color wheel on top right corner shows the flow direction for the different colors in the velocity map (background image). The scale bar is a wavelength $(\lambda)$.

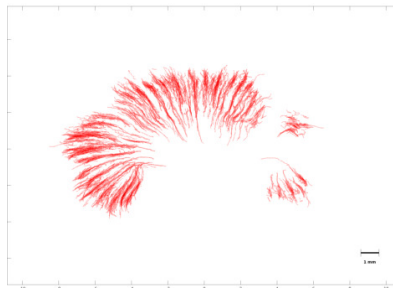

(a) Arteriole tracks

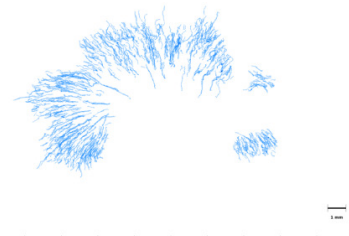

(b) Venules tracks

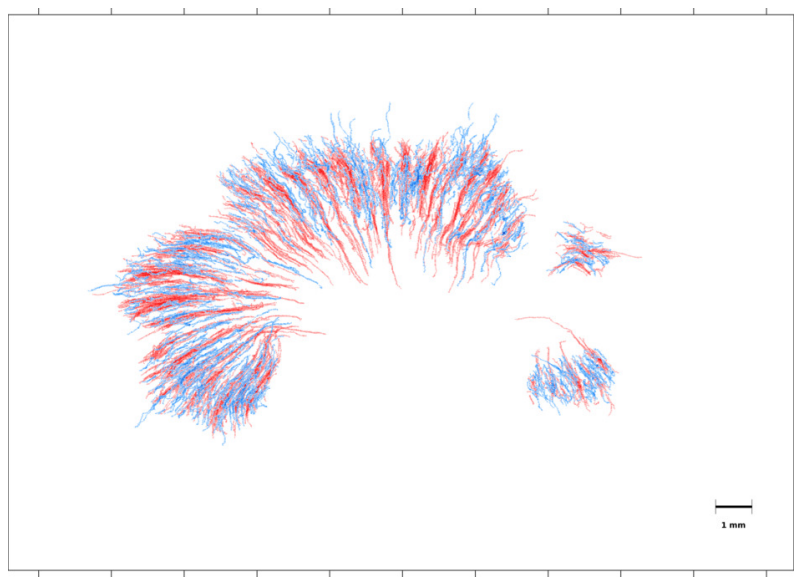

(c) Fusion of the two classes

Fig. 2: Classified tracks of the outer medulla into groups of arterioles and venules

\section{RESUlts AND Discussion}

The tracks after classification are shown in Fig. 2. The red tracks are for descending flow direction, showing the descending vasa recta. The blue tracks are showing the trajectories of MBs with opposite flow directions and depict the ascending vasa recta. Many of the MBs will be disrupted, when they are exposed to the ultrasound for a longer time. This could be explain the abundance of MBs and their trajectories in the descending vasa recta (Fig 2.a) compared with ascending ones (Fig. 2.b).

A moving average over the instantaneous blood velocity of the two groups of tracks is shown in Fig. 3, demonstrating

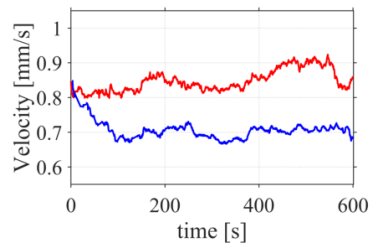

(a) Rat 1

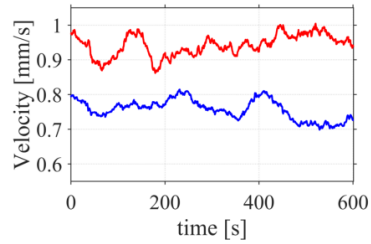

(c) Rat 3

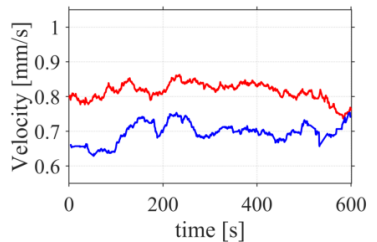

(b) Rat 2

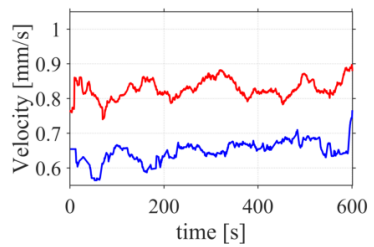

(d) Rat 4
Fig. 3: The moving average blood velocity in the arterioles (red) and venules (blue) of the outer medulla in 4 healthy kidneys. The moving average window size is 1 minute. In all the cases, a lower velocity in the venules were observed.

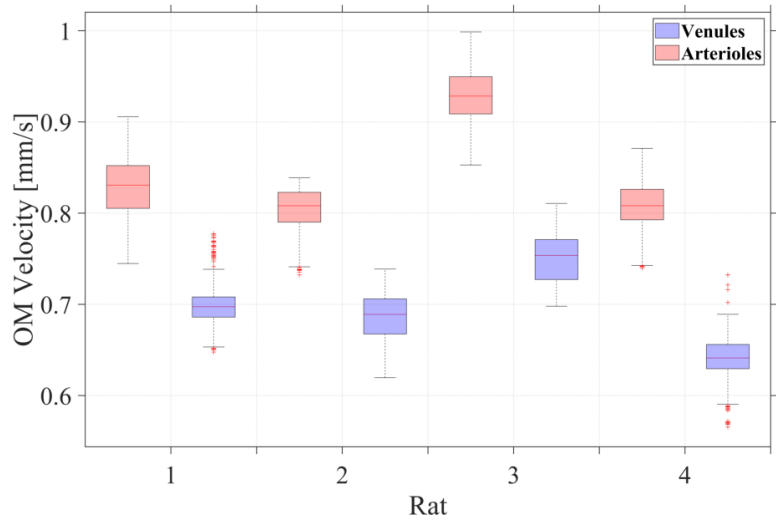

Fig. 4: Velocity distribution in the outer medulla (OM)

that the velocity of blood in the arterioles of the outer medulla was higher compared with the blood velocity in the venules. This result was consistent among all 4 rats and the Wilcoxon signed ranked test on the median velocity in the two groups of arterioles and venules of the 4 rats showed that the difference of the velocity estimates for the classified tracks were statistically significant $(p=0.002)$. This is also immediately perceivable from box plots shown in Fig. 4. The $95 \%$ confidence interval of median velocity in arterioles and venules of the outer medulla for the 4 rats were in the range of $0.84 \pm 0.09 \mathrm{~mm} / \mathrm{s}$ and $0.70 \pm 0.07 \mathrm{~mm} / \mathrm{s}$, respectively.

\section{CONCLUSION}

This paper presented a method for classification of arteries and veins based on track filtration and a priori anatomical information. The method showed that the median of estimated velocities in the classified group of tracks was statistically significantly different. In all 4 cases, the median velocity in the arterioles of the outer medulla were consistently higher than the median velocity its venules. 


\section{ACKNOWLEDGMENT}

This work was financially supported by grant 82-2014-4 from the Danish National Advanced Technology Foundation, by grant 7050-00004B from Innovation Fund Denmark, and from BK Medical, Herlev, Denmark.

\section{REFERENCES}

[1] W. N. McDicken, G. R. D. Sutherland, C. M. Moran, and L. N. Gordon, "Color Doppler velocity imaging of the myocardium," Ultrasound Med. Biol., vol. 18, no. 6-7, pp. 651-654, 1992.

[2] J. Rubin, R. Bude, P. Carson, R. Bree, and R. Adler, "Power Doppler US: a potentially useful alternative to mean frequency-based color Doppler US," Radiology, no. 190, pp. 853-856, 1994.

[3] J. A. Jensen, S. I. Nikolov, A. Yu, and D. Garcia, "Ultrasound vector flow imaging I: Sequential systems," IEEE Trans. Ultrason., Ferroelec., Freq. Contr., vol. 63, no. 11, pp. 1704-1721, 2016.

[4] _ - "Ultrasound vector flow imaging II: Parallel systems," IEEE Trans. Ultrason., Ferroelec., Freq. Contr., vol. 63, no. 11, pp. 1722-1732, 2016.

[5] S. B. Feinstein, B. Coll, D. Staub, D. Adam, A. F. Schinkel, J. Folkert, and K. Thomenius, "Contrast enhanced ultrasound imaging," Journal of nuclear cardiology, vol. 17, no. 1, pp. 106-115, 2010.

[6] Y. Desailly, J. Pierre, O. Couture, and M. Tanter, "Resolution limits of ultrafast ultrasound localization microscopy," Phys. Med. Biol., vol. 60, no. 22, pp. 8723-8740, 2015.

[7] K. Christensen-Jeffries, R. J. Browning, M. Tang, C. Dunsby, and R. J. Eckersley, "In vivo acoustic super-resolution and super-resolved velocity mapping using microbubbles," IEEE Trans. Med. Imag., vol. 34, no. 2, pp. 433-440, February 2015.

[8] C. Errico, J. Pierre, S. Pezet, Y. Desailly, Z. Lenkei, O. Couture, and M. Tanter, "Ultrafast ultrasound localization microscopy for deep superresolution vascular imaging," Nature, vol. 527, pp. 499-502, November 2015.

[9] K. Christensen-Jeffries, O. Couture, P. A. Dayton, Y. C. Eldar, K. Hynynen, F. Kiessling, M. O'Reilly, G. F. Pinton, G. Schmitz, M. Tang et al., "Super-resolution ultrasound imaging," Ultrasound Med. Biol., vol. 46, no. 4, pp. 865-891, 2020

[10] S. B. Andersen, I. Taghavi, C. A. V. Hoyos, S. B. Søgaard, F. Gran, L. Lonn, K. L. Hansen, J. A. Jensen, M. B. Nielsen, and C. M. Sørensen, "Super-resolution imaging with ultrasound for visualization of the renal microvasculature in rats before and after renal ischemia: A pilot study," Diagnostics, vol. 10, no. 11, p. 862, 2020.

[11] J. A. Jensen, S. B. Andersen, C. A. V. Hoyos, K. L. Hansen, C. M. Sørensen, and M. B. Nielsen, "Tissue motion estimation and correction in super resolution imaging," in Proc. IEEE Ultrason. Symp., 2019, pp. $1-4$.

[12] I. Taghavi, S. B. Andersen, C. A. V. Hoyos, M. B. Nielsen, C. M. Sørensen, and J. A. Jensen, "In vivo motion correction in super resolution imaging of rat kidneys," IEEE Trans. Ultrason., Ferroelec., Freq. Contr., p. Early Access, 2021.

[13] I. Taghavi, S. B. Andersen, C. A. V. Hoyos, M. Schou, S. H. Øygard, F. Gran, K. L. Hansen, C. M. Sørensen, M. B. Nielsen, M. B. Stuart, and J. A. Jensen, "Tracking performance in ultrasound super-resolution imaging," in Proc. IEEE Ultrason. Symp., 2020, pp. 1-4. 